\title{
Realization and Application of Multimedia Video System Based on Web Server in Teaching of Engineering Measurement
}

\author{
http://dx.doi.org/10.3991/ijet.v11i05.5691 \\ Xiaorong Wang \\ Jiangsu Financial Vocational College, Lianyungang, China
}

\begin{abstract}
In recent years, a new teaching mode - multimedia video system has risen sharply with the rapid development of network technology, computer hardware and software technology and multimedia technology. As the carrier of a new teaching environment, network teaching supplements traditional teaching mutually, extends the limit of space and time, creates a new path of independent study and provides an effective and feasible approach for the realization of continuing education, education for all and life-long education. This paper studies the architecture of multimedia video system and key technologies for its realization from the perspective of WEB server realization technology in combination with FLV (Flash Video) streaming media technology and meanwhile verifies the application effect of the online teaching video system. According to the teaching experiment, multimedia video system based on web server has far better teaching effect and results in higher learning initiative and satisfaction of students than traditional teaching in the experimental teaching of Engineering Measurement.
\end{abstract}

Index Terms-web server, multimedia video system, FLV streaming media technology

\section{INTRODUCTION}

As a new teaching environment and means, network teaching system has aroused more attention of researchers with the progress of science and technology and the need of modern development of education [1]. There have been some web-based teaching systems on market. Some influential platforms in the world include WEBCT [2], Blackboard [3] and IBM's E-Learning [4] etc., where Blackboard Learning System offers powerful teaching environment for teachers and students, and virtual environment for students. It can achieve personalized customization according to the need of course learning. Besides, it regards "teaching", "connection" and "sharing" as the core objectives and offers a set of comprehensive, complete and optimized solutions [3]. Massive open online course is a recent online course development mode, which evolves from resource distribution and learning management system as well as new course development mode which integrates learning management system and more open network resources. Besides, it is also the largest IT skill learning platform in China at present, which can offer abundant mobile terminal development, php development, web front end, android development, html5 and other video course resources [5-7]. Although overseas webbased teaching systems are advanced technically, not all are suitable for the education in China [8]. Chinese aca- demic and education department also starts to study and independently develop web-based education platform. China Ambow Group took the lead to put forward development of Ambow "learning engine" (called Ambow Learning Engine), and first applied "Ambow open remote education platform v1.0" software system and formulated 3A design idea, i.e. Assess. Analyze and Adjust. This is system innovation based on the theory of Adaptive Learning [9]. Sky class web-based teaching system is a webbased teaching platform with complete free downloading functions and advanced technology. This platform constructs three teaching systems for teachers and sets up corresponding functions according to the three teaching systems, including "knowledge" - (resource), "task" (assignment testing) and "communication - (question answering, discussion, chatting and email) [10]. China has achieved great progress in research and independent development of web-based teaching platform, but there are still some problems. Different web-based teaching platforms are independently researched and developed by diverse companies or schools, and they adopt different data structure, development tools and databases. Thus, cross-platform application and web-based teaching resource sharing have obstacles. It is difficult to carry out data exchange in different teaching platforms [11]. The development of the above Chinese web-based teaching platforms aims at middle school and primary school education, while the web-based teaching platforms are very few. Undergraduates are a large consumption group for development of vocational education and remote education technology. At present, the effects of some online multimedia teaching are not ideal. For example, blocked streaming media transmission results in the poor application effect. FLV is a new video format, called Flash Video [12]. Because of such advantages as very small file and very fast loading speed, it is very fluent to watch video files. It effectively solves the defect that the exported SWF file cannot be well used on network due to huge size after video file is imported in Flash [12]. Secondly, there are many players which support FLV playing, such as QQ Player, Core Player, Baidu Player and KM Player. Thus, it is beneficial for popularization and application.

Therefore, this research, based on WEB server technology, combines FLV streaming media technology to design a multimedia video system based on WEB server, carries out feasibility analysis of such online teaching video system and verifies the application effect by the experiment. The experimental course is engineering measurement. This research offers reference for further optimizing online multimedia system. 


\section{Design Of Multimedia Video System Based ON WEB SERVER}

The structure of multimedia video system based on web server designed in this paper mainly includes master computer, multimedia system, local server, internet, LAN, switch and personal computer etc.

\section{A. Design structure diagram of multimedia video system based on web server}

As shown in Figure 1, the video system structure includes three layers: data server layer, information submission application server and client application layer. Data server layer mainly includes upper-layer information submission database server and video server. Information submission application server contains information submission middleware and corresponding management software etc. Client application layer mainly includes information utilization software and web browser information submission software. Besides, safety guarantee system runs through the three layers and is responsible for data operation and flow security of he whole data layer [13].

Figure 2 shows structure diagram of web-based multimedia video system. It can be seen from the figure that the master computer is connected with multimedia system; the multimedia system is connected with local server through picture pick-up system and recording system; LAN is connected with the local server; LAN can send data (including character, picture, video and audio etc.) to personal computer via multimedia video system. Internet is connected with the local server through the switch, and can send data to personal computer through multimedia video system. In the whole state, for a service territory, local server, LAN and video system are used to send media file to users. In addition, individual client can acquire multimedia resource through internet access.

\section{B. System function module of multimedia video system based on web server}

Figure 3 shows function module diagram of multimedia teaching video system. The whole multimedia video system mainly includes two modules: teaching support system and teaching management system. Teaching support system is mainly oriented to application function, and two major teaching activity modules are listed, including question answering and discussion, online questions and answers, course assignment and experts' lecture. Teaching management system serves for application function, including user management, system setting, system announcement management and course management. system platform setup is the architecture of universal version. Since web-based multimedia system is oriented to different objects, technical support system and management system will differ.

\section{Multimedia video system display based on web server}

Multimedia video teaching system applies common remote course platform navigation style in terms of page navigation, and adopts list directory display form to present corresponding online courses for students, as shown in Figure 4 and 5.

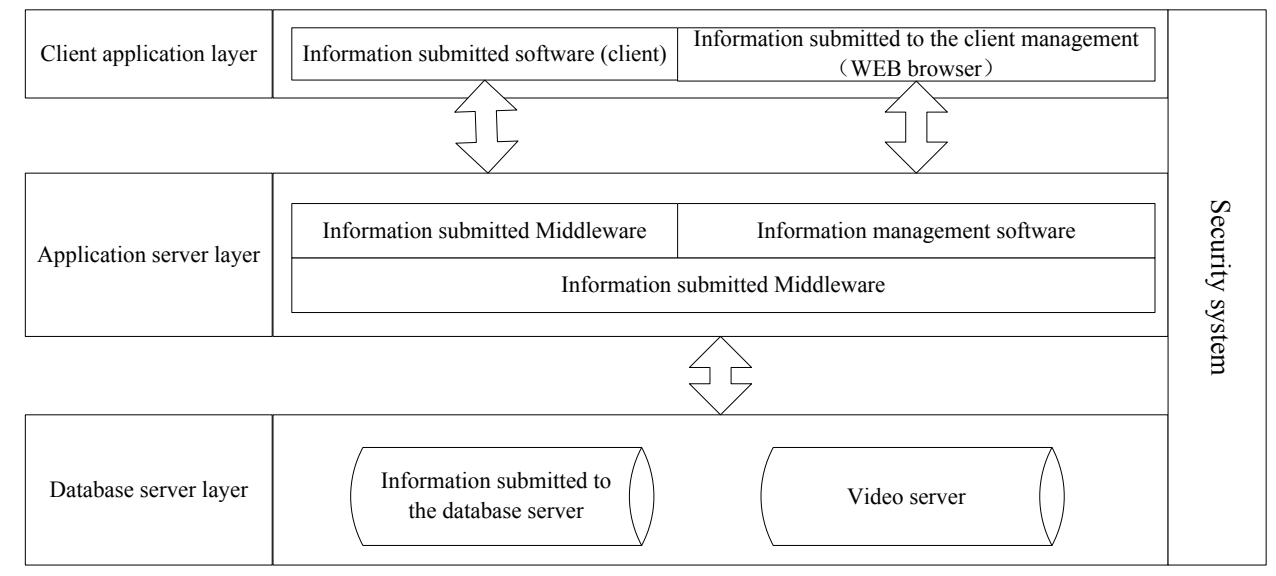

Figure 1. Schematic diagram of vedio system structure

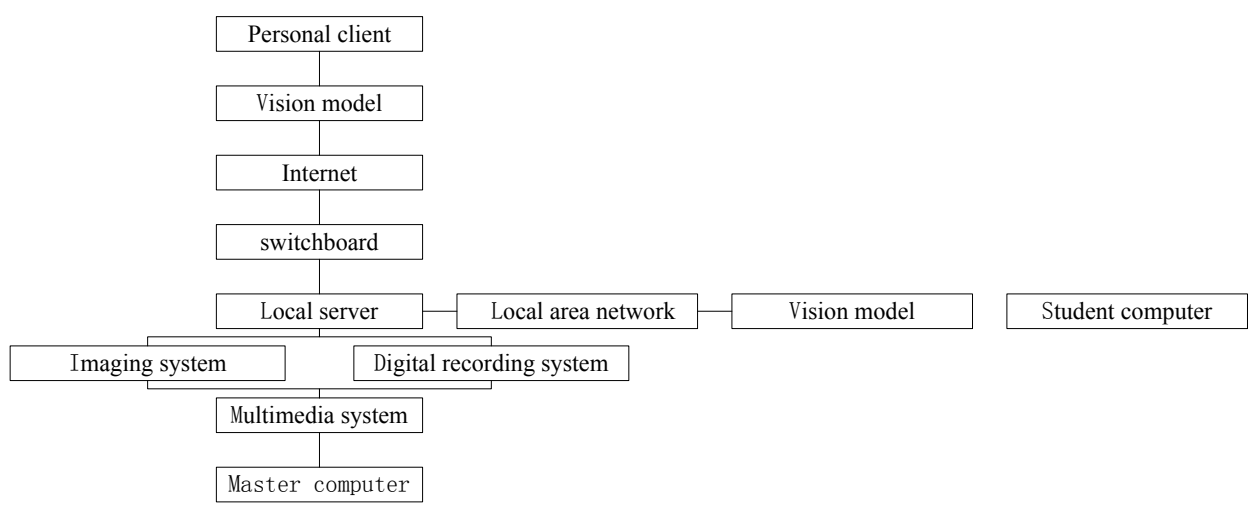

Figure 2. Schematic diagram of video system structure 
PAPER

Realization and Application of Multimedia Video System Based on Web Server in Teaching Of EngineE...

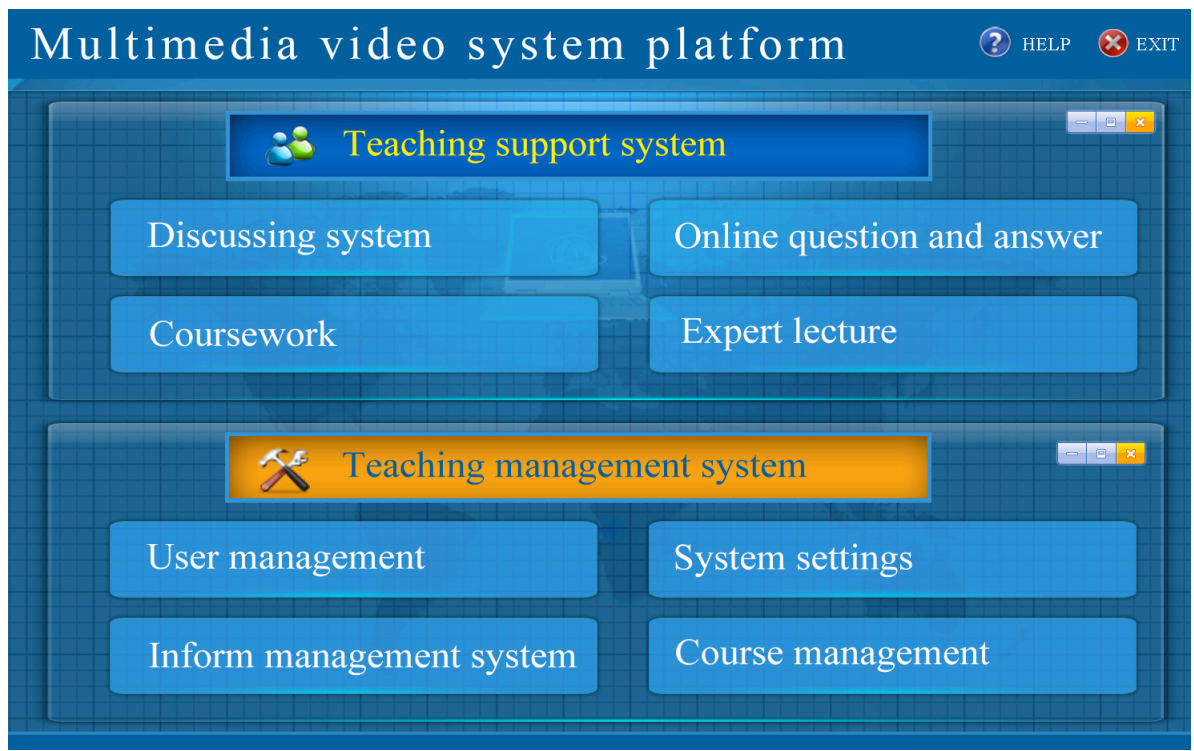

Figure 3. Function module diagram of multimedia video

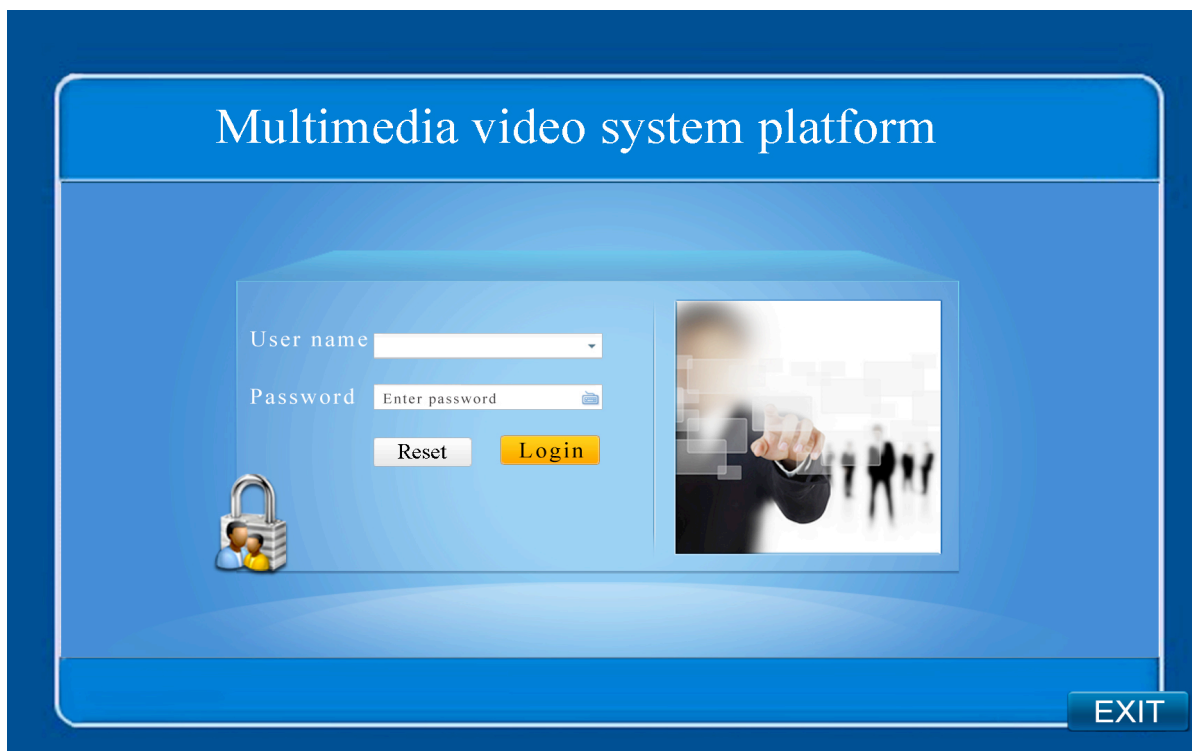

Figure 4. Multimedia video system navigation based on web server

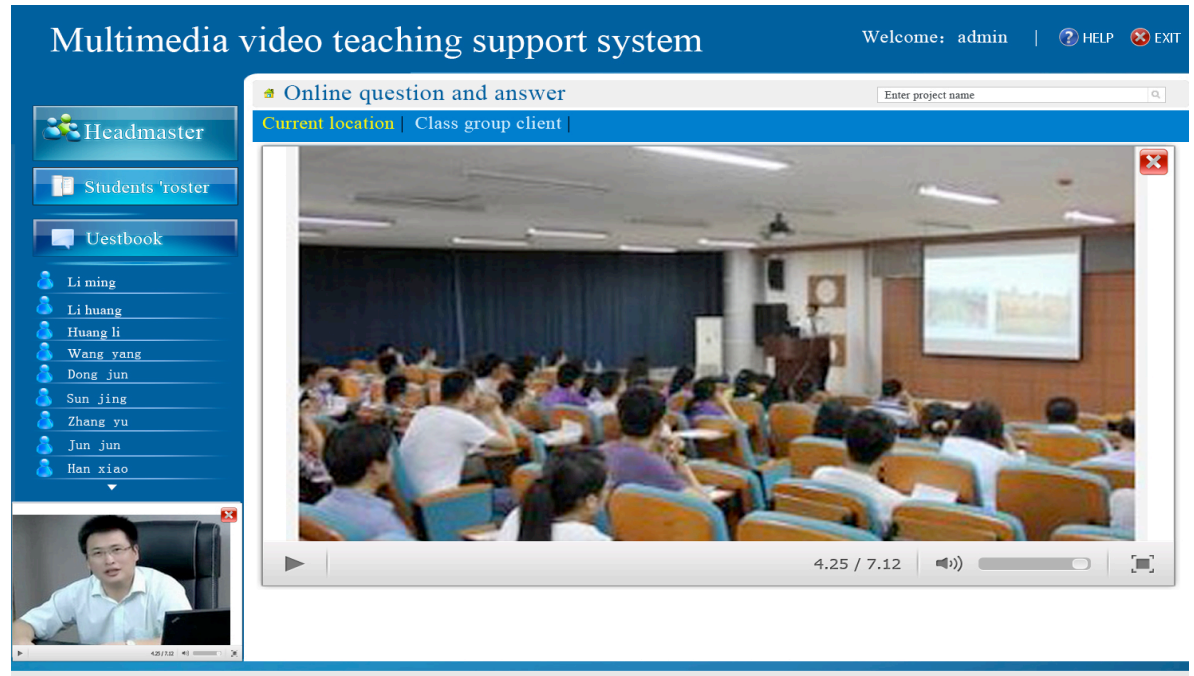

Figure 5. Multimedia video system interface based on web server 


\section{Features of multimedia video system based on web server}

(1) The system can achieve remote synchronous teaching and has strong interactivity. Besides, it can permanently preserve course resources. The course content will be automatically saved in the remote server.

(2) Signing system is equipped in the multimedia video system. It can help teachers count students' attendance in the teaching process and gain feedback information in time.

(3) Through setting interactive system in LAN and internet, the interaction from system terminal to terminal can be achieved. In the teaching process, teachers may interact with students any time.

(4) The system sets cryptosystem which can effectively prevent disclosure of course resources and infringement of course copyright. The application of the system in bad commercial publicity can be effectively prevented.

\section{Application Of Multimedia Video System BASED ON Web SERVER IN COURSE TEACHING}

\section{A. Objects of experiment}

200 undergraduates of clinical medicine with five-year academic system who took engineering measurement as an elective course were chosen as the objects of study, including 80 students in Grade 2012, 60 students in Grader 2013 and 60 students in Grade 2014. The students in Grade 2012 were set as traditional teaching group, and single teacher's teaching was applied. The students in Grade 2013 and 2014 were set as multimedia video teaching group, and they were taught by multimedia video system. Gender composition of the two groups has no statistical significance, and teaching content of the students in both groups are same.

\section{B. Course setting and teaching method}

Engineering measurement is a core course of engineering construction major, which has 48 periods. Its main objective is to allow students to master the basic knowledge and theory of engineering measurement, basic methods for measurement and setting-out of engineering factors (angle, distance and altitude difference) and methods for processing basic measurement data through the study of the course. In addition, students should also master working principles and usage of various conventional engineering measurement instruments.

(1) Traditional teaching: the teacher as the subject teaches basic knowledge of engineering measurement through verbal explanation.

(2) Multimedia video system teaching based on web server: online video teaching method is adopted according to course content. All course contents are taught to students through pictures, sound, video and other multimedia modes. In classroom, students can interact and exchange with the teacher, and the atmosphere is relaxing and active. Students may change course sequence at will according to their interests and hobbies, as long as they can complete all course contents within the specified time. Moreover, students may form groups spontaneously to discuss course contents and after-class assignments.

\section{Teaching effect evaluation method}

After the course was finished, the 200 students who took engineering measurement as an elective course were required to fill out the self-designed questionnaires for successive 3 years, of which the contents include: understanding of necessity of the course, interest, teaching content, teaching method, satisfaction, harvest, etc. There were 200 questionnaires given out, and 200 effective questionnaires were collected back. Meanwhile, the student symposium was held to, in the form of interview, understand students' harvest after they finished this course, their opinions and suggestions about this course.

\section{Statistical method}

The SPSS16.0 software was adopted to enter the data and make a statistics, mainly including descriptive analysis of the data, classified variable data counting rate and constituent ratio; the chi-square test and Wilcoxon ranksum test were adopted for comparison of inter-group rate and constituent ratio, and the testing level is $\alpha=0.05$.

\section{E. Result}

(1) Comparison between the two groups of students with respect to their interest in engineering measurement and satisfaction with course arrangement:

The traditional teaching group of students' satisfaction (including 'basically satisfied' and 'satisfied') with the course is $68.7 \%(55 / 80)$, and the interest rate (including 'interested' and 'very interested') is $75 \%$ (111/120). According to the comparison of satisfactions and interest rates of different groups of students accepting different teaching methods, the differences are statistically significant $(\mathrm{P}<0.001)$, as shown in Table I.

(2) Comparison between two groups of students' understanding of necessity of course learning:

Among the students accepting the traditional teaching, 12 of them $(15.0 \%)$ thought that it was unnecessary to learn this course, 50 of them $(62.5 \%)$ thought that it was necessary, and the remaining 18 of them (22.5\%) thought that it was very necessary. Among the students accepting the multimedia video teaching, 10 of them (8.3) thought that it was unnecessary to learn this course, 65 of them $(54.2 \%)$ thought that it was necessary, and 45 of them $(37.5 \%)$ thought that it was very necessary; the difference of comparison between the two groups is statistically significant $(Z=2.433, P=0.015)$. Thus it can be seen that the two groups of students accepting different educational processes have a significantly difference in understanding of the same course. It can be clearly seen from the abovementioned data that the offering of the course engineering measurement is generally accepted by students accepting the video teaching, which indicates that they learned more knowledge and understanding from this course.

(3) Comparison between two groups of students with respect to their harvest in scientific research knowledge and ability after learning this course

After the two groups of students finished their learning of this course, we interviewed them with respect to their research topic selection, material analysis, data analysis, paper writing, paper evaluation and survey capability. Detailed results are shown in Table II. 
PAPER

Realization and Application of Multimedia Video System Based on Web SERVER in Teaching Of EngineE...

TABLE I.

TWO GROUPS OF STUDENTS' INTEREST AND SATISFACTION WITH THE COURSE ENGINEERING MEASUREMENT

\begin{tabular}{l|c|c|c|c|c|c|c}
\hline \multirow{2}{*}{ Group } & \multirow{2}{*}{$\mathbf{n}$} & \multicolumn{3}{c|}{ Satisfaction } & \multicolumn{3}{c}{ Interest Rate } \\
\cline { 3 - 8 } & & Not Satisfied & $\begin{array}{c}\text { Basically Satis- } \\
\text { fied }\end{array}$ & Very Satisfied & Not Interested & Interested & Very Interested \\
\hline Traditional Teaching & 80 & $25(31.2 \%)$ & $30(37.5 \%)$ & $25(31.3 \%)$ & $20(25.0 \%)$ & $32(40.0 \%)$ & $28(35.0 \%)$ \\
\hline Multimedia Video Teaching & 120 & $10(8.3 \%)$ & $50(41.7 \%)$ & $60(50.0 \%)$ & $9(7.5 \%)$ & $54(45.0 \%)$ & $57(47.5 \%)$ \\
\hline$\chi^{2}$ & & \multicolumn{3}{|c|}{$<0.001$} & & 11.86 \\
\hline P-value & & \multicolumn{3}{|c|}{0.001} \\
\hline
\end{tabular}

TABLE II.

RESULTS OF INTERVIEWING TWO GROUPS OF STUDENTS WITH RESPECT TO ENGINEERING MEASUREMENT

\begin{tabular}{|c|c|c|c|c|c|}
\hline Contents & Specific Items & $\begin{array}{c}\text { Traditional Teaching } \\
\text { Group }\end{array}$ & Multimedia Video Teaching Group & $x^{2}$ & $\mathbf{P}$ \\
\hline \multirow{7}{*}{$\begin{array}{l}\text { What harvest do you } \\
\text { get after taking this } \\
\text { course? }\end{array}$} & Research topic selection & $45(56.3)$ & $85(70.8)$ & 4.49 & 0.034 \\
\hline & Material analysis & $48(60.0)$ & $80(66.7)$ & 0.93 & 0.336 \\
\hline & Data analysis & $36(45.0)$ & $82(68.3)$ & 10.80 & 0.001 \\
\hline & Paper writing & $36(45.0)$ & $65(54.2)$ & 1.61 & 0.204 \\
\hline & Paper evaluation & $32(40.0)$ & $60(50.0)$ & 1.93 & 0.164 \\
\hline & Survey capability & $38(47.5)$ & $72(60.0)$ & 3.03 & 0.082 \\
\hline & Others & $13(16.3)$ & $18(15.0)$ & 0.06 & 0.811 \\
\hline
\end{tabular}

It can be seen from the above Table that the multimedia video teaching method can effectively improve students' abilities of data analysis and research topic selection, which are $23.3 \%$ and $14.5 \%$ higher than those of the traditional teaching group. Thus, the multimedia video system teaching based on web server is more effective than the traditional teaching.

\section{CONCLUSION}

It can be seen from the above analysis that the multimedia teaching system based on web server plays a big role in engineering measurement teaching, leading to great changes in teaching content, method and mode. It can not only improve students' skills of mastering professional knowledge, but also enhance their attention to course learning.

(1) The contents of the course engineering measurement are abstract but strongly practical. It is discovered, from the comparison between traditional teaching dominated by "teacher's teaching" and online multimedia video system teaching, that the online multimedia video teaching is superior to the traditional teaching with respect to teaching effect and improving students' learning initiative, basic research literacy and capability, etc.; the above result is consistent with the multimedia teaching experiment report by Jia [12] and Xie [13]. The multimedia video system applied in this research can carry out the online discussion with teachers and students of other colleges and answer questions at any time, further improving students' initiative, enhance their enthusiasm in participating in self-regulated learning, improving their interest in learning and their abilities in all other aspects.

(2) The multimedia video system adopts computer, network and communication technologies as well as scientific and standard management to merge, integrate and fully digitalize all information related to learning, teaching, scientific research, management and life service, so as to constitute unified user management, resource manage- ment and access control. It places particular emphasis on providing students with access to campus network and Internet through Wifi to obtain learning resources easily and providing teachers with convenience in using wireless network to check students' learning condition at any time, complete their lesson preparation and conduct scientific researches; the implementation of such paperless teaching improves teachers' work efficiency and increases interactions between teachers and students; especially, the teaching contents of this course are dominated by "literature consulting", learning research methods, writing scientific research papers, etc.; the video form based on WEB network helps students consult teachers while searching relevant knowledge and is good for improving their learning effect.

(3) Timely face-to-face man-machine interaction and one-to-one immediate feedback are outstanding technical characteristics of this system. The multimedia computer further combines the audio-visual integration function of television and the interaction function of computer, producing a new way of illustrated and colorful man-machine interaction, and the immediate feedback can be realized. Its video-visual integration arouses, in a multi-angle way, students' emotion, attention and interest. Its dynamic nature is beneficial to showing the concept and process, effectively breaking through teaching difficulties. Its interaction makes students participated more frequently and more active in learning, and creates the environment of introspection to help students form a new cognitive structure through the creation. The multimedia experiment achieves the expansion of general experiments, and the reconstruction and simulation of real scenes cultivate students' exploration and creation abilities. Its repeatability is good for breaking through teaching difficulties and overcoming the loss of memory, and its pertinence makes it possible to teach students of different levels. It large amount of information and high capacity save space and time, improving the teaching efficiency. 
To sum up, the research indicates that the interaction of multimedia video system based on web server is significant for teaching process; it can effectively arouse students' learning interest and strong learning desire, which consequently forms the learning motivation. Its audiovisual integration can break through visual constraint, realize the object observation in a multi-angle way and highlight key points, promoting the concept understanding and method mastering; this kind of online teaching video system has a wide application prospect.

\section{REFERENCES}

[1] Liaw S.S., Huang H.M., "Enhancing Interactivity in Web-based Instruction: A Review of the Literature," Educational Technology, vol. 40, no. 3, pp. 41-45, May-Jun 2000.

[2] Shi D.Y., Li W.Y., MU L.H., Zhang Q.J., "Practice and exploration of calculation method of network courses based on WebCT," Journal of Science of Teachers' College and University, no. 4, pp. 30, August 2013.

[3] Liaw S.S., "Investigating students' perceived satisfaction, behavioral intention, and effectiveness of e-learning: A case study of the Blackboard system," Computers \& Education, vol. 51, no. 2, pp. 864-873, September 2008. http://dx.doi.org/10.1016/j.compedu. 2007.09.005

[4] Welsh E.T., Wanberg C.R., Brown K.G., Simmering M.J., "Elearning: emerging uses, empirical results and future directions," International Journal of Training and Development, vol. 7, no. 4, 245-258, November 2003. http://dx.doi.org/10.1046/j.13603736.2003.00184.x

[5] Pappano L., "The Year of the MOOC," The New York Times, vol. 2, no. 12, pp. 1-7, November 2012.

[6] Breslow L., Pritchard D.E., DeBoer J, Stump G.S., Ho A.D., Seaton D.T., "Studying learning in the worldwide classroom: Research into edX's first MOOC," Research \& Practice in Assessment, vol. 8, no. 1, pp. 13-25, January 2013.
[7] Yin B.S., Li Y., "MOOCs Development and Its Inspirations to Open Universities," Journal of Beijing Radio and TV University, no. 5, pp. 29-34, May 2013.

[8] Feng L.C., "Design of Multimedia Teaching System Based on WEB," Network Security Technology \& Application, no. 7, pp. 214-215, July 2014.

[9] Shen J., Yu H.Z., Wang F.C., Yan M.M., "Modern distance education system design based on J2EE and MVC," Journal of Changchun Institute of Technology (Natural Sciences Edition), vol. 11, no. 1, pp. 89-92, February 2010.

[10] Xie Y.C., Gao J., "Discussion on Construction and Application of University Campus Network Courses-Based on "Sky-Classroom" Network Teaching Platform," E-Commerce, no. 7, pp. 92-94, July 2010.

[11] Yan K.X., "Discussion on Application of Streaming Media Technology Based on Flv," China Educational Technique \& Equipment, no. 15, pp. 106-107, August 2011.

[12] Jia H.L., "Brief Discussion on Application of Multimedia Courseware in Teaching," China Education Innovation Herald, no. 23, pp. 175, December 2011.

[13] Xie S.X., "Development and Research of Multimedia Teaching Resource Application System Based on Web," Computer Knowledge and Technology (academic exchange), no. 13, pp. 215216, July 2007.

\section{AUTHOR}

Xiaorong Wang (Corresponding author) is an associate profession in Jiangsu Financial Vocational College, Lianyungang 222003, China. Her research interests include multimedia video system and web server (wangxiaorong2@yeah.net)

Submitted 29 March 2016. Published as resubmitted by the author 29 April 2016. 